NHS administration are dragging their feet. The old psychiatric hospitals have seen themselves as bastions of sanity and are naturally opposed to moves to take their power and responsibility away. Consultants who regard themselves as above other professionals are not likely to make best use of and develop the skills of those that they are increasingly called to work with. The resistance to the proposal of community psychiatry is threatening to the medical monarchy and its somewhat feudal administration. Surely, though, it must be time for a psychiatric reformation.

The Rowans Rehabilitation Hostel

Geoff LAYToN

Birmingham

Dear Sirs

Dr Hugh Freeman, in his paper 'Training for Community Psychiatry' (Bulletin, February 1985, 9, 29-32) does not mention that this is a setting where Large Group therapy is appropriate.

I am the Founder of a voluntary organization in Wimbledon known as the Messenger House Trust. This has been in existence for some 15 years and for most of that time much of our therapeutic work has been done through our Large Group. In fact, my experience of conducting this small open group gave me the confidence to start a Large Group at the Wallington Day Centre last November where staff and patients sit in a single circle talking to each other. Mothers bring their children and I was particularly pleased to welcome a visiting professor who came with her dog! Doctors, clergy, social workers and community psychiatric nurses are invited to attend with their clients and those they wish to help.

The Large Group plays a dual role in the realm of community psychiatry. It provides a setting for diagnostic-therapy, and importantly, also for training. The Large Group way of working potentiates my diagnostic skills. It also encourages a psychotherapeutic way of thinking by the patients, and in addition it provides a framework in which those who are training learn to listen and observe.

Further papers on the work of the Messenger House Trust Large Group are available on request.

Messenger House Trust

JOSEPHINE M. LOMAX-SIMPSON

8 Malcolm Road

London SW19

\section{Behaviour problems in the mentally handicapped-literature search}

DeAr Sirs

We should like to draw the attention of your readers to the fact that we have just started a literature search on the behaviour problems manifested by mentally handicapped people. This is funded by the DHSS and will take two years, after which we shall produce a bibliography and a critical review of the field.

We should be grateful for any information on this subject that your readers may wish to give us- (correspondence and enquiries to Joyce Hamilton).

\section{J. M. Hamilton \\ K. A. DAY \\ P. S. SMITH}

Mental Handicap Services Unit

Northgate Hospital

Morpeth, Northumberland

\section{Register of computer users}

Dear Sirs

We suspect that there are many College members who, like ourselves, are using computers at their place of work, perhaps to aid data storage, research, teaching or for patient interaction. We feel sure that a list of users and their lines of interest would be a useful aid to the expansion of this area.

With this in mind we would be very pleased if interested colleagues could supply us with the following information: makes of computers, disk or tape storage, uses to which they are put, additional hardware and publications or studies in this area. It would also be useful to know about software that people are writing and whether they would be interested in exchanging programmes or ideas.

Once this information is compiled we will circulate it to those on the list and also to the College Library.

If this initial enquiry is successful we will update the records on a regular basis.

Whitchurch Hospital

Martin Briscoe GARETH JoNES

Cardiff

\section{Gothic horror?}

\section{DeAR SIRS}

I was sorry to see that the Bulletin has followed the example of the College in resorting to a Gothic typescript for the word 'Bulletin'. I wonder if I am alone in the College at bewailing its use of this type of script. It always seems to me that our general medical colleagues see psychiatry as sometimes representing medicine in the nineteenth century. Under these circumstances it is a pity that the College should allow its publications to perpetuate this image.

St George's Hospital

JOHN M. KELLETT

Blackshaw Road, London SW17 